\title{
Os Partidos Uruguaios: a transição na transição
}

\author{
Jorge Lanzaro \\ Instituto de Ciencia Política, \\ Universidad de la República, Uruguai
}

\begin{abstract}
Resumo
Este artigo analisa a transição e a vitalidade atual do sistema partidário uruguaio. Após um período de crise, que culminou com o rompimento da democracia nos anos sessenta, nos anos noventa o sistema partidário recupera sua centralidade conduzindo o processo de transição democrática. Durante esse processo, observa-se o realinhamento do sistema partidário, que tende a tornar-se um sistema de multipartidarismo moderado, com o amadurecimento e fortalecimento da esquerda, representada sobretudo pelo Frente Amplio. O crescimento deste último deveu-se à sua capacidade de confrontar os partidos tradicionais e também por seu desenvolvimento como partido "catch-all", marcado pela reconversão ideológica e competição pelo centro, conforme aumentavam suas chances eleitorais. 0 crescimento do Frente Amplio implicou ainda, para os partidos tradicionais, o ingresso em um processo de aprendizagem de compromisso e participação em governos de coalizão e, para o processo de transição liberal, a formação de um quadro de distâncias ideológicas moderadas, sem polarização. Todavia, a clivagem esquerda-direita serve ainda de eixo para a competição eleitoral.
\end{abstract}

Palavras-chave: partidos políticos, democratização, Frente Amplio, sistema partidário

\begin{abstract}
This article analyses the political transition and the current vitality of the Uruguayan party system. After a period of crisis that lead to the rupture of democracy in the seventies, in the nineties the party system retrieved its centrality in the process of the democratization. During this process, the party realignment resulted in a moderate multipartysm, with a strengthened left, mainly represented by the Frente Amplio. The rise of the Frente Amplio resulted of its capacity to confrontate the traditional parties, its evolution as a catch-all organization, its ideological transformation and electoral performance. To the traditional parties this process promoted the learning of political compromises and participation in government coalitions; to the process of liberal transition, it resulted in a political scenery with moderate ideological distances, without polarization. However, the left-right parameters still defines the axis of electoral competition.
\end{abstract}

Key words: political parties, democratization, Frente Amplio, party system 
Em tempos de changement d'époque, como o que estamos vivendo atualmente na América Latina e em todo o mundo, as transformações na política e nos modelos de desenvolvimento exigem e provocam mudanças nos partidos, que podem ser analisadas caso a caso - levando-se em conta a evolução de um único partido -, mas que também estão relacionadas com as características e mudanças registradas em todo o sistema partidário ${ }^{1}$.

Análises comparativas oferecem exemplos de partidos ou sistemas partidários que não sobreviveram às fases de transformação aguda - as "conjunturas críticas" (COLLIER e COLLIER, 1991), que podem ser vistas como períodos de "darwinismo político" (COPPEDGE, 2002). Há também exemplos de partidos e sistemas partidários que conseguem atravessar essas fases e liderar as mudanças, ao abraçar um caminho de auto-transformação, com as dificuldades de serem "mutantes" eles mesmos e com graus variados de sucesso. Isso pode envolver todos ou alguns dos membros anteriores do sistema partidário, ou criar espaço para o surgimento de novos partidos ou mesmo sistemas partidários inteiramente novos.

Os tempos atuais, tal como outras fases históricas de mudança, delineiam uma "estrutura de oportunidades" que não provoca necessariamente um declínio dos partidos, como algumas abordagens sugerem. Talvez leve a situações de crise, mas pode abrir caminho para a renovação dos partidos e para o desenvolvimento do sistema partidário onde se tenham mostrado consistentes, e mesmo nos países onde partidos e sistemas partidários eram débeis. Essas alternativas (party-ness party-less) são fatores determinantes para a qualidade da democracia e a qualidade dos processos de reforma.

O sistema partidário uruguaio, originalmente um sistema bipartidário com uma história de 150 anos e um alto grau de institucionalização (MAINWARING e SCULLY, 1995), gozou de longos períodos de prosperidade ${ }^{2}$. Porém, experimentou um período de dificuldades durante a década de 1930 e uma grande crise nos anos 60 , que terminou num rompimento da democracia.

\footnotetext{
1 Uma análise sobre a "persistência e mudança" em partidos e sistemas partidários que abrange as duas dimensões, pode ser encontrada em MAIR (1997).

${ }^{2}$ Sotelo (1999) confirma que os partidos tradicionais uruguaios estão entre os mais antigos das Américas e da Europa ocidental (segundo ou terceiro lugar, dependendo do critério usado). Com relação aos sistemas partidários, se forem classificados de acordo com uma "longevidade exitosa" - idade média dos dois partidos mais votados na última eleição incluída no estudo (1994) - o Uruguai está em primeiro lugar, seguido pelos Estados Unidos e pela Colômbia. O crescimento do FA e o fato de ter sido o partido mais votado em 1999 , "rejuvenescem" o sistema partidário uruguaio e lhe fazem descer pontos no ranking internacional de antigüidade, sem que perca, não obstante, a consistência que os anos lhe têm dado.
} 
Nas duas últimas décadas, entretanto, os partidos e o sistema partidário recuperaram seu papel e sua centralidade, proporcionando as chaves para o "governo de partidos" (party government ${ }^{3}$ ) durante um período de transição "dual": a) restauração da democracia após mais de dez anos de ditadura; b) agenda de reformas estruturais (Estado, economia, políticas sociais). Essa "segunda" transição está dominada pelas tendências neoliberais, mas, devido à competição política, as reformas têm uma inclinação gradualista e moderada, que põe limites à liberalização e mantém, em boa medida, a centralidade do Estado (LANZARO, 2000a).

Nesse contexto, os partidos uruguaios sofreram uma espécie de "transição na transição" com duas dimensões. Em primeiro lugar, há um realinhamento do sistema partidário, do bipartidarismo tradicional para um multipartidarismo moderado, em conseqüência do desenvolvimento da frente política de esquerda Frente Amplio (FA) que desafia os "decanos" do clube - o Partido Colorado (PC) e o Partido Nacional (PN). Estes continuam no páreo, mas tendem a formar um bloco político. Em segundo lugar, produzem-se mudanças substanciais nas funções dos partidos, em sua organização e estratégias políticas.

Ligando as duas dimensões, este artigo analisa a evolução dos dois blocos partidários e a "prosperidade" que cada um consegue, tanto no governo como na oposição, apontando para os paradoxos resultantes de seus próprios desempenhos:

1. Os partidos tradicionais (colorados e blancos) lideraram o esforço para realizar reformas estruturais e, assim fazendo, sofreram uma alteração substantiva. Afastaram-se das práticas do keynesianismo e do "welfare state" (propensas à intervenção estatal e ao protecionismo, clientelismo e corporativismo) e impulsionaram a liberalização e a "volta ao mercado", no que se refere à economia e à reforma do Estado. Estes processos implicam mudanças na política e na intermediação política, nos padrões de liderança e cidadania, "linkages" e legitimação. Na medida em que a oposição de esquerda cresceu, os modos de governo também foram inovados - com a formação de coalizões no regime presidencialista - e foi promovida uma grande reforma do sistema eleitoral, a partir de 1996.

\footnotetext{
3 O "governo de partidos" - "party government" (cf. entre outros, Castles e Wildenmann, 1986) - envolve a predominância de partidos na representação política e tomada de decisões, recrutamento, socialização e disciplina das equipes políticas e autoridades públicas, formação de opinião, desempenho eleitoral e ligações com cidadãos e grupos, capacidade de governo e oposição, liderança e autonomia, legitimação e accountability dentro do quadro das instituições políticas (regras formais e informais) e um sistema de competição que assegura, ao mesmo tempo, integração e fidelidade. Esses elementos referem-se a um processo permanente de produção e reprodução (produtividade política, acomodação e controle), mas estão sujeitos a desafios extraordinários em tempos de mudança, que envolvem a transformação da política e, ao mesmo tempo, exigem a reestruturação dos partidos.
} 
Essas estratégias revelaram-se custosas. Enquanto bloco, os partidos tradicionais ainda mantêm um importante apoio eleitoral, mas vêm, sistematicamente, perdendo votos (de um total combinado de $76 \%$ em 1984 para $55 \%$ em 1999).

Pretendo explicar essa tendência com base nos efeitos combinados de dois fatores em jogo: a) a transição liberal que os próprios partidos promoveram, em particular a transformação de sua antiga condição de partidos de Estado e partidos "keynesianos", por meio de um processo que, embora apresente alguns resultados positivos, implica uma redução de seus recursos políticos tradicionais e b) os padrões de competição e cooperação - provocados pelo desenvolvimento do Frente Amplio como um terceiro partido desafiante - que levaram os partidos tradicionais à associação política e à convergência ideológica. E, na esteira disso, os efeitos do novo sistema eleitoral, que tende a reforçar a competição bipolar, baseada na clivagem esquerda-direita.

2. À esquerda do espectro, o Frente Amplio torna-se a força hegemônica de oposição e consegue uma notável ascensão eleitoral (de 21\% em 1984 para 40\% em 1999). Essa prosperidade pode ser explicada em função de: a) seu desenvolvimento como partido "catch-all" e "eleitoral", mantendo, contudo, a "fraternidade" com sindicatos e movimentos sociais; b) sua estrutura de "partido de coalizão", unificando todos os grupos de esquerda e c) sua estratégia oposicionista, contra a liberalização e as privatizações, em defesa da tradição estatista, que está combinada, de fato, com as tendências para a moderação ideológica e a competição pelo centro.

Porém, o FA precisa agir num contexto de competição exigente e deve encarar as contradições que derivam de seu próprio desenvolvimento: a) afirmandose na oposição e, ao mesmo tempo, apresentando-se como uma alternativa de governo e b) avançando na reconversão ideológica e assumindo posições políticas que são cada vez mais "pragmáticas", mantendo ao mesmo tempo sua identidade e a "lógica da diferença" para com os outros partidos.

Com esses parâmetros, a experiência da esquerda uruguaia pode ser comparada à de outros partidos de esquerda da Europa e da América Latina, levando-se particularmente em conta os diferentes "caminhos" para o governo que seguiram as agrupações de esquerda mais exitosas da região, especialmente no Brasil e no Chile.

Este trabalho oferece uma visão geral dos padrões de mudança e da vitalidade do sistema partidário uruguaio, que estão condicionados pelo passado histórico e que surgem do processo político distinto que comanda a transição nas últimas décadas. O caso uruguaio possui certas vantagens quando comparado com outros países latino-americanos, quais sejam, as questões derivadas das estratégias 
partidárias no governo e na oposição, em um quadro de competição bipolar, reforçado por novas regras eleitorais e animado pela divisão esquerda-direita e o caminho gradualista da transição liberal no interior de um padrão de mudança que preserva a centralidade do Estado e os recursos políticos em maior medida do que em outros países.

\section{O sistema político do bipartidarismo tradicional}

Os Partidos Colorado e Nacional surgiram no século XIX como fundadores do Estado-nação e, baseados numa equação de poder relativamente equilibrada, construíram uma democracia pluralista, do tipo "consociacional".

Esse sistema baseava-se em quatro pilares: a) regime eleitoral com "voto simultâneo duplo" (no partido e nos candidatos do partido) ${ }^{5}$ b) eleição presidencial por pluralidade e representação proporcional "integral" no parlamento; c) "co-participação" de ambos os partidos nos conselhos de serviços estatais e juntas de controle (com uma distribuição de assentos entre maiorias e minorias semelhante à "propoz" austríaca) ; d) maiorias parlamentares especiais para leis e nomeações estratégicas. A maior parte desses princípios de competição e coparticipação foi resultado de acordo entre as elites partidárias antes da democratização e do sufrágio universal, seguindo o caminho de uma "poliarquia" (DAHL, 1971), sem hegemonia ou relações privilegiadas com os trabalhadores e os outros setores populares "incluídos".

"Os vencedores não levam tudo": as regras constitucionais garantem a competição efetiva e, apesar de os colorados terem dominado durante muitas décadas, os partidos mantiveram um certo equilíbrio eleitoral, num contexto de

\footnotetext{
4 Lijphart (1969) cunhou seu bem conhecido conceito de democracia "consociacional" em referência aos processos de construção nacional "associativa", em sociedades atravessadas por divisões sociais (de nacionalidade, etnia, religião, classe). Creio que essa noção possa ser aplicada aos processos de construção nacional que se baseiam numa clivagem centro-periferia, mesmo em casos como o do Uruguai, em que os partidos não representam simplesmente divisões sociais e econômicas, mas funcionam como partidos catch-all, articulados em conflitos realmente políticos, referidos originalmente ao estabelecimento do poder central do Estado. Assim, as linhas de clivagem baseiam-se em tradições e subculturas políticas, numa composição similar à da Colômbia.

${ }^{5}$ As eleições nacionais incluem as eleições "internas": as frações dentro do partido competem umas com as outras, ao mesmo tempo em que acumulam votos juntas para competir com os outros partidos. Essa fórmula valia para todos os postos - com vários candidatos de cada partido (para a presidência, o parlamento e os municípios) - favorecendo a permanência de frações e redes de arregimentação eleitorais.
}

${ }^{6}$ Em dois períodos (1913-33 e 1951-67), a co-participação chegou ao ápice do Poder Executivo, por meio de um conselho de governo semelhante ao da Suiça. 
poderes compartilhados, com acesso plural ao Estado e ao processo governamental, que abrangia a maioria e proporcionava lugares para as minorias.

O Uruguai possui um regime presidencialista "pluralista", que inclui algumas experiências de governo de coalizão, mas funciona, em larga medida, como um "presidencialismo de compromisso", moldado pela "co-participação" e por acordos "transversais" entre governo e oposição".

Os dois partidos são partidos de Estado num Estado de partidos (Parteienstaat), com a função dupla de representação e governo, mantendo o domínio dos circuitos públicos para a tomada de decisões políticas e a alocação de recursos $^{8}$. Ligado à sua "captura" do Estado, os partidos tinham suas próprias organizações densamente estruturadas e estavam firmemente implantados nas mais diversas áreas da sociedade civil $^{9}$.

No Uruguai, como em outros países pequenos e dependentes, o Estado desempenhou historicamente um notável papel central e desde o começo do século XX tornou-se um Estado "ampliado", assumindo funções estratégicas no desenvolvimento da economia e da sociedade (nacionalização de bancos, empresas e serviços, regulamentação de mercados e do trabalho, educação pública, previdência social). As evoluções sucessivas multiplicaram as intervenções do Estado e moldaram nosso keynesianismo "crioulo"10. Desde a democratização originária, a integração política está amarrada à integração social, mediante

\footnotetext{
${ }^{7}$ Levando em conta a experiência do Uruguai e dos Estados Unidos, bem como a recente evolução de alguns países latino-americanos, sustentei que os regimes presidencialistas - bem como os parlamentaristas - podem ser classificados como democracias "majoritárias" ou "populistas", mas também "pluralistas" com base em distribuição do poder, instituições governamentais e sistemas partidários, estilos de liderança e cultura política (LANZARO, 2000 e 2001). Essa abordagem segue Dahl (1956) e Lijphart (1984), mas diverge da crença de que os sistemas presidencialistas são por natureza majoritários. Nos textos mencionados, também faço a distinção entre "presidencialismo de coalizão" (ABRANCHES, 1988) - com gabinetes multipartidários - e "presidencialismo de compromisso", em que um executivo partidário busca acordos parlamentares com outros partidos, frações legislativas ou representantes individuais, caso a caso ou segundo linhas de alianças, mas sem montar um governo de coalizão.

${ }^{8}$ Embora possa haver certas semelhanças, a noção de partidos de Estado não se identifica com a de partidos "cartel" (KATZ e MAIR, 1995), uma abordagem polêmica que busca caracterizar a evolução recente dos partidos em democracias avançadas. A idéia de partidos de Estado é mais ampla e remonta a extensos períodos da história, abrangendo diferentes modelos de desenvolvimento, formas de Estado e funções partidárias.

$9 \mathrm{Na}$ década de 1930, as instituições estatais dominadas pelos partidos tradicionais no regime de "coparticipação" se articularam com outros organismos reguladores, com representantes de classe, formando um segmento corporativo (co-participação corporativa). Contudo, blancos e colorados mantiveram seus perfis de partidos de cidadãos, de representação individual e territorial. Nesse contexto, recebiam amplo apoio eleitoral da classe trabalhadora, mas não controlavam os sindicatos, cuja liderança continuava nas mãos dos partidos de esquerda.
}

\footnotetext{
${ }^{10}$ A partir de 1930, vemos um avanço do capitalismo "assistido", com uma economia "fechada", que mantém seu foco agroexportador ao mesmo tempo em que desenvolve uma industrialização voltada para o mercado interno (ISI).
} 
ligações que deixam marcas duradouras na cidadania (política e social) e na cultura cívica.

Os partidos tradicionais participam da construção do Estado e negociam sua expansão, moldando sua estrutura política e agindo como "governantes permanentes", numa posição de dominação em relação à burocracia e com uma forte conexão com agentes sociais e grupos de interesse. Mais do que qualquer outro fator, os partidos agem como detentores da liderança política - ancorada no Estado - que se torna o principal motor dos projetos nacionais, do desenvolvimento econômico e da integração social, num país "novo" e "pequeno", encravado entre dois vizinhos grandes e altamente dependente dos centros de poder do mundo.

Desde a crise de 1930 - e mesmo antes, avant la lettre - eles se desenvolveram como partidos "keynesianos" (LANZARO, 1994) ${ }^{11}$, isto é, projeto nacional, liderança política e governo combinavam-se com responsabilidades diretas na produção e distribuição de bens públicos, regulação econômica e mediação dos conflitos sociais. Os partidos conduziam essas atividades mediante programas públicos gerais, benefícios sociais universais e serviços estatais, mas também por meio de prestações seletivas, particularismo, clientelismo e ligações corporativas, com uma ampla margem para decisões discricionárias.

Esses fenômenos selam a relação Estado-sociedade e mantêm as alianças de classe e o "compromisso nacional" no qual se baseia o modelo de desenvolvimento. Também marcam os poderes e estratégias dos partidos, seus recursos políticos e articulações, seus apoios e os padrões de legitimação. Os partidos controlam o Estado e, por sua vez, dele dependem, em larga medida.

Em resumo, ao longo do século $X X$, o regime eleitoral e as regras de competição entre os partidos e as frações partidárias, a "co-participação" e o sistema pluralista de governo, junto com o papel central do Estado, a reitoria "keynesiana" e os benefícios do bem-estar social contribuíram para perpetuar a hegemonia dos partidos tradicionais - em sua condição de partidos de Estado e ligações com a sociedade civil - possibilitando uma participação eleitoral muito alta e um compromisso dos cidadãos com a política e os partidos. Como veremos, as mudanças políticas em curso e as ações dos próprios partidos tradicionais, em relação às reformas estruturais e ao desafio do Frente Amplio, solaparam as bases dessa supremacia.

\footnotetext{
${ }^{11}$ Aplico aos partidos o nome que Pizzorno (1980) atribui aos sindicatos da "era keynesiana".
} 


\section{Realinhamento do sistema de partidos}

Nos anos 60, o esgotamento do modelo de desenvolvimento levou a uma crise econômica estrutural e abriu caminho para a crise política. O fracasso do sistema partidário foi decisivo nesse processo. Os partidos tradicionais não conseguiram descobrir um modo de renovar-se ou renovar seu projeto político, o Estado e a economia, perdendo centralidade, seu papel de liderança e sua capacidade de combinar interesses. A "inércia" de seus hábitos anteriores e o fardo do particularismo pesou sobre eles. Assim, encontraram dificuldades insuperáveis para montar um projeto alternativo, um novo compromisso político e novas alianças sociais. As iniciativas de reforma foram bloqueadas pela competição entre os partidos e frações partidárias em um ciclo que intensificou a fragmentação política e as oposições sociais. Houve um intenso ativismo de grupos de pressão e associações de classe, que se transformou numa espécie de "corporatização" da política. Os sindicatos reuniram suas forças em uma única confederação e passaram a atuar como um eixo da mobilização política.

Foi nesse contexto que ocorreram os primeiros avanços da esquerda, por meio de eleições e movimentos de massa, em paralelo a algumas ações guerrilheiras. Em 1971, os velhos partidos "ideológicos" (socialistas, comunistas, democratas cristãos) uniram-se com grupos independentes e com frações dos partidos tradicionais para fundar o Frente Amplio, que nas eleições daquele ano abriu uma brecha no domínio bipartidário.

Em conseqüência da competição centrífuga, do distanciamento ideológico e de oposições radicais, o Uruguai entrou - de acordo com a "cartografia" de Sartori em um pluralismo "polarizado", que desembocou no golpe de 1973 e na ditadura militar, da qual o país só sairia em 1985.

O realinhamento foi preservado no novo estágio da democracia, mas com um pluralismo "moderado", tendo em vista o número de partidos, suas posições ideológicas e o padrão de competição em direção ao centro ${ }^{12}$.

O FA desenvolveu-se como um terceiro partido graças à sua metamorfose e ao seu desempenho eleitoral. Apesar da separação que originou o Nuevo Espacio (NE), um partido pequeno, composto por grupos centristas, o FA apresentou um crescimento sustentado, com dois saltos eleitorais importantes em nível nacional e três vitórias consecutivas para o governo de Montevidéu, onde vivem $42 \%$ da população do país, além de uma expansão mais recente no resto do país.

\footnotetext{
${ }^{12}$ O número efetivo de partidos no parlamento aumentou de $2.7 \mathrm{em} 1971$ para $3.1 \mathrm{em} 1999$. Uma pesquisa de 1999 (Equipos-Mori) registra uma distância ideológica relativamente moderada no espectro partidário: Frente Amplio 3.3, Nuevo Espacio 4.94, Partido Nacional 7.48, Partido Colorado 7.59. A máxima distância ideológica é 4.3 e nenhum partido está localizado em um extremo.
} 
OPINIÃO PÚBLICA, Campinas, Vol IX, no 2, Outubro, 2003, pp. 46-72

Tabela 1

Votos em eleições nacionais - 1971-1999 (\%).

\begin{tabular}{||c|c|c|c|c|c|c||}
\hline & 1971 & 1984 & 1989 & 1994 & $1999-I$ & $1999-I I$ \\
\hline Partido Colorado & 41 & 41 & 30 & 32 & 33 & 54 \\
\hline Partido Nacional & 40 & 35 & 39 & 31 & 22 & - \\
\hline Frente Amplio & 18 & 21 & 21 & 31 & 40 & 46 \\
\hline Nuevo Espacio & - & - & 9 & 5 & 5 & - \\
\hline
\end{tabular}

Tabela 2

Eleições nacionais: Votos em Montevidéu (\%).

\begin{tabular}{||c|c|c|c|c|c|c||}
\hline & 1971 & 1984 & 1989 & 1994 & $1999-\mathrm{I}$ & $1999-\mathrm{II}$ \\
\hline Partido Colorado & 39 & 36 & 25 & 27 & 30 & 44 \\
\hline Partido Nacional & 30 & 27 & 27 & 21 & 13 & - \\
\hline Frente Amplio & 30 & 34 & 34 & 44 & 52 & 56 \\
\hline Nuevo Espacio & - & - & 13 & 7 & 5 & - \\
\hline
\end{tabular}

Tabela 3

Eleições nacionais: Votos no Interior (\%).

\begin{tabular}{||c|c|c|c|c|c|c||}
\hline & 1971 & 1984 & 1989 & 1994 & $1999-I$ & $1999-$ II \\
\hline Partido Colorado & 42 & 46 & 35 & 37 & 35 & 62 \\
\hline Partido Nacional & 48 & 42 & 49 & 40 & 30 & - \\
\hline Frente Amplio & 10 & 10 & 10 & 19 & 31 & 38 \\
\hline Nuevo Espacio & - & - & 6 & 4 & 4 & - \\
\hline
\end{tabular}

Tabela 4

Eleições municipais: Montevidéu (\%).

\begin{tabular}{||c|c|c|c|c|c||}
\hline & 1971 & 1984 & 1989 & 1994 & $\mathbf{2 0 0 0}$ \\
\hline Partido Colorado & 40 & 36 & 25 & 27 & 28 \\
\hline Partido Nacional & 30 & 27 & 25 & 21 & 12 \\
\hline Frente Amplio & 30 & 34 & 37 & 45 & 58 \\
\hline Nuevo Espacio & - & - & 13 & 7 & 1 \\
\hline
\end{tabular}

Como se pode ver, o FA tem apresentado uma implantação principalmente urbana - e fortemente concentrada em Montevidéu - embora recentemente tenha também expandido-se em nível nacional, com dois saltos eleitorais importantes no conjunto dos departamentos do interior do país (1994 e 1999). 


\section{Tabela 5}

Distribuição de votos do FA: Montevidéu - Resto do País (\%)

Eleições nacionais - 1971-1999.

\begin{tabular}{|c|c|c|c|c|c|}
\hline Votos do FA & 1971 & 1984 & 1989 & 1994 & 1999 \\
\hline Montevidéu & 70 & 74 & 75 & 65 & 56 \\
\hline Resto do País & 30 & 26 & 25 & 35 & 44 \\
\hline
\end{tabular}

Fonte: Instituto de Ciência Política, Banco de Dados.

No nível nacional, a volatilidade eleitoral é bastante moderada ${ }^{13}$. O realinhamento do sistema partidário ocorreu mediante uma série de eleições "críticas", mas desdobrou-se gradualmente, sem mutações abruptas, como mostra a própria evolução do FA, incluindo três períodos na prefeitura de Montevidéu e outras experiências de iniciação política (Parlamento, Corte Eleitoral, Tribunal de Auditores), que promoveram a socialização entre os quadros do FA e relações com outros centros da elite, embalando um eventual estágio no governo nacional.

\section{Tabela 6}

Volatilidade eleitoral 1971-1999 (Índice Pedersen).

\begin{tabular}{||c|c|c|c|c|c|}
\hline & 1971 & 1984 & 1989 & 1994 & 1999 \\
\hline Volatilidade & 8.9 & 5.2 & 13.3 & 11.6 & 10.0 \\
\hline
\end{tabular}

Fonte: Chasquetti 2000.

\section{Tabela 7}

Volatilidade eleitoral inter-blocos 1971-1999 (Índice Pedersen).

\begin{tabular}{|l|c|c|c|c|c||}
\hline & 1971 & 1984 & 1989 & 1994 & 1999 \\
\hline Volatilidade & 4,6 & 3,9 & 8,0 & 5,6 & 8,7 \\
\hline
\end{tabular}

Fonte: Instituto de Ciência Política - Banco de Dados.

O processo ocorreu, portanto, em um contexto de estabilidade democrática e não provocou a desarticulação do sistema partidário. Os partidos mais antigos continuam em funcionamento e o FA tem se movido em um cenário de integração política e competição rigorosa, comparável ao das sociais-democracias européias e outros partidos de esquerda latino-americanos (Brasil, Chile, México).

\footnotetext{
${ }^{13}$ Uma tabela de Mainwaring e Scully (1995), que abrange doze países latino-americanos para o período 197189 , mostra que o Uruguai tem a volatilidade mais baixa $(9,1 \%)$.
} 


\section{A "segunda" transição}

Os partidos se reconstituíram como principais atores da transição democrática. Finalizada a ditadura, eles enfrentaram os desafios de uma "segunda" transição, com o processo de reformas estruturais - longo e laborioso - que alterou o modelo de desenvolvimento predominante durante a maior parte do século XX e que acarretou mudanças significativas no desenho político e no próprio sistema partidário.

\section{O bloco dos partidos tradicionais}

O PC e o PN tomaram a iniciativa de levar a cabo a transição liberal. Atuando como "agenda setters", promoveram a reforma política, estatal e econômica através das ações de governo, do debate ideológico e das campanhas eleitorais e por meio de políticas "negativas" e "positivas": ajuste fiscal, privatização, mudanças nas funções do Estado e liberalização econômica, com novas formas de regulação da economia e da sociedade. Dessa forma, os partidos precisaram, ao mesmo tempo, reconverter-se e deixar de lado sua condição de partidos "keynesianos".

Esses processos foram atravessados pela competição entre partidos e entre frações de partidos, envolvendo os setores "modernizadores" e "conservadores". Para impulsionar as reformas e enfrentar a resistência provocada por esse processo, ocorreram movimentos no sentido da centralização dentro dos partidos e do governo, tendendo a reforçar o Executivo. Porém, apesar dessas tendências no sentido de concentração, que são universais e têm efeitos perversos em outros países latino-americanos, o Uruguai manteve um certo equilíbrio de poder. Não houve governo "por decreto" e as reformas passaram regularmente pelo Parlamento e por negociações entre partidos. Além disso, houve vários casos relevantes de participação dos cidadãos em consulta "direta", como plebiscitos sobre questões constitucionais e referendos para bloquear a privatização de grandes empresas públicas.

Na medida em que a oposição de esquerda crescia, a aliança entre o PN e o PC se reforçou, dando origem a uma "política de blocos". Os partidos tradicionais revezaram-se na Presidência, entraram num processo de aprendizagem de cooperação e compromisso e começaram a montar governos de coalizão ${ }^{14}$. Isso

\footnotetext{
${ }^{14} \mathrm{O}$ caso uruguaio soma-se às experiências de coalizão em regimes presidencialistas registradas em outros países latino-americanos, como novidade ou com precedentes (LANZARO, 2001). A partir dos anos 80, o presidencialismo de coalizão (ABRANCHES, 1988) surge como um produto de certas condições políticas da nova "onda" de democracia: sistemas multipartidários, geralmente com eleições majoritárias do presidente, em dois turnos, ajustes econômicos e reformas estruturais, em um ciclo de transformações substantivas da política e dos partidos. Ao contrário do que alguns autores prevêem, a "combinação difícil" de presidencialismo e multipartidarismo (MAINWARING, 1993) não conduz necessariamente a um "impasse" ou a ameaças à
} 
Ihes permite compor maiorias parlamentares, sustentar políticas liberais e promover reformas do Estado que são, todavia, "incrementais": a competição entre os parceiros da coligação e a oposição do FA tendem a impor um caminho gradualista, com moderação das iniciativas políticas (ex ante e ex post).

Com o objetivo de retardar o acesso do FA ao governo - ou para tornar essa possibilidade dependente de um apoio político maior (evitando a "síndrome de Salvador Allende") - os partidos tradicionais promoveram uma reforma constitucional em 1996, que desmantelou o regime eleitoral que havia possibilitado seu desenvolvimento desde o início do século XX. O novo modelo eliminou o duplo voto simultâneo e, em vez do antigo princípio da pluralidade, adotou a regra da maioria com dois turnos para as eleições presidenciais (ballottage), que permite apenas um candidato por partido (escolhido em eleições primárias compulsórias e simultâneas para todos os partidos). Porém, mantém o sistema de representação proporcional nas eleições parlamentares, que coincidem com o primeiro turno da eleição presidencial.

A dupla lógica desse sistema favorece a pluralidade partidária e também o alinhamento em blocos. Todos podem competir no primeiro turno para a representação proporcional no Parlamento e por uma chance no segundo turno presidencial. Os partidos próximos podem reagrupar-se para o segundo turno e o modelo induz às coalizões eleitorais - destinadas a se tornarem coalizões de governo, tendendo para a bipolaridade: multipartidarismo bipolar, não necessariamente bipartidarismo ou polarização ${ }^{15}$.

\section{A evolução do Frente Amplio}

A "segunda" transição delineia uma "estrutura de oportunidade". O FA mostrou-se capaz de tirar vantagem desse "momentum" e, mediante uma evolução política proveitosa, tornou-se um partido exitoso, com expansão eleitoral sustentada, alimentando expectativas de que poderia conquistar o governo nacional.

Esse progresso pode ser explicado, em primeiro lugar, pelo fato de que o FA capitalizou o "descontentamento" criado pelas principais orientações do governo (GONZÁLEZ, 1999) e mostrou-se como uma alternativa. Isso ocorreu, em larga

\footnotetext{
democracia, mas pode encontrar rotas apropriadas para o governo e as reformas, mesmo em períodos de turbulência e mudança brusca. Também fica claro que as coalizões de governo não são exclusivas do sistema parlamentarista, como geralmente se acredita.

${ }^{15}$ Esses são os efeitos encontrados comumente em eleições majoritárias de dois turnos, combinadas com representação proporcional (DUVERGER, 1951; SARTORI, 1994). Os sistemas multipartidários bipolares - que "dão ordem" à pluralidade no sistema partidário - também prosperam em outros países latino-americanos, em composições mais rígidas (Chile) ou mais flexíveis (Brasil).
} 
medida, porque o FA se apresentou como paladino dos valores que estão profundamente arraigados na cultura política do país, defendendo posições estatistas, distributivas e igualitárias que se desenvolveram no Uruguai durante o século XX. Com efeito, o FA compete por essas tradições contra os partidos tradicionais $^{16}$.

Mas o avanço do FA responde também à transformação política pela qual a esquerda uruguaia se desenvolve como um partido "catch-all", com as características que Kirchheimer (1966) descreve, embora com traços específicos decorrentes de sua história e trajetória atual (LANZARO, 1996 e 2000b).

O Frente Amplio conseguiu afirmar sua identidade ao mesmo tempo em que passava por uma significativa metamorfose, combinando o velho e o novo na linhagem da esquerda:

1) Ele afastou-se das características dos partidos "ideológicos" para adotar posições políticas mais pragmáticas e cada vez mais moderadas. Não obstante, manteve um grau de formalização programática relativamente alto (ALCÁNTARA \& FREIDENBERG, 2001), reivindicando os elementos genéricos do repertório da esquerda, alguns dos quais - em particular o estatismo e o igualitarismo - são velhos componentes da cultura política uruguaia.

2) Embora retenha em parte seus traços de partido de massa, tornou-se mais um partido "eleitoral" (PANEBIANCO, 1982).

3) Sua convocatória diversificou-se e sua condição de partido de "integração" (NEUMANN, 1980), com referentes de classe e uma forte "fraternidade" com o movimento operário, deu lugar a uma "política dos cidadãos" e um novo perfil "popular", com maior espaço para a representação individual e os votantes "soltos". Contudo, manteve os laços com os sindicatos, ainda que as relações mútuas sejam cada vez mais autônomas e, por vezes, conflitantes. Cultivou também sua vocação de esquerda "social", mediante temas de discurso e por meio de uma rede de relações com grupos velhos e novos, renovando suas antigas raízes e tomando alguns espaços onde os partidos tradicionais costumavam reinar;

\footnotetext{
${ }^{16}$ A defesa do Estado e a oposição às privatizações é um dos cavalos de batalha do FA (embora isso seja menos forte no contexto do governo municipal). Essa situação combina bem com a forte cultura estatista do povo uruguaio, indo muito além do âmbito dos partidários do FA. Os eleitores de esquerda têm uma clara preferência pelo Estado e se opõem às privatizações, mas nem todos os cidadãos a favor do Estado estão alinhados com a esquerda. Em um referendo de 1992, mais de $70 \%$ dos eleitores foram a favor da anulação da lei que autorizava a privatização de algumas empresas públicas (em particular, a venda da companhia telefônica). Oito anos depois, $81 \%$ dos uruguaios acreditavam que o Estado deveria ter maioria na propriedade das grandes empresas públicas, opinião compartilhada por $90 \%$ dos que se identificavam como de esquerda, $82 \%$ dos que se diziam centristas e $71 \%$ dos que afirmavam ser de direita. Porém, a "desmonopolização" é vista com melhores olhos ( $50 \%$ dos respondentes a consideram positiva, inclusive $44 \%$ dos que se consideram de esquerda). Ao mesmo tempo, $48 \%$ dos respondentes acham que é positivo incorporar capital privado para desenvolver as empresas públicas e $35 \%$ consideram essa opção negativa (Cf. CIFRA, 2000).
} 
4) Ao mesmo tempo, ocorreram mudanças em sua organização, em seus processos de decisão e estrutura de liderança. Ao nível do conjunto do FA, a organização de massas é mais flexível do que era há alguns anos (ou, pode-se dizer, até mais "fina", de acordo com as categorías de Gunther \& Diamond, 2003). Mas o grau de "articulação" política (DUVERGER,1951) permanece bastante forte, em termos de organismos comuns de decisão e de bancada parlamentar, do líder partidário, assim como da disciplina e coesão (embora neste plano haja focos visíveis de discordância e desobediência).

Em todo caso, há um certo declínio do "apparatchik", dos "devotos" e dos militantes do comitê, acompanhado da emergência de uma nova geração de "profissionais". Continuamente surgem novos líderes que constróem carreiras e conquistam o poder como candidatos eleitorais e autoridades públicas.

\section{Da coalizão de partidos ao "partido de coalizão"}

O Frente Amplio, que começou como uma coalizão de partidos, transformouse num "partido de coalizão" (LANZARO, 1996) ${ }^{17}$. Ao lado dos partidos fundadores do $F A$, os grupos que surgiram como novos setores dentro da coalizão têm peso político. Nem os novos, nem os velhos são partidos autônomos: são, na verdade, frações de um conglomerado que é maior do que a soma de suas partes e que constitui uma estrutura unificada com uma identidade abrangente e tradição própria.

Mesmo enquanto partido "novo", o FA construiu uma identidade forte e sua própria tradição (um processo de "tradicionalização"), com base nos legados históricos e trajetórias que começaram com sua criação, por meio da resistência contra a ditadura e desde a transição democrática. Afirma-se assim o processo de integração política do movimento de esquerda e sua "nacionalização" (no sentido de Gramsci, 1971), que começou nos anos 60 e que, inclusive, deu origem ao FA em 1971. Em anos recentes, o FA é comparativamente o partido que retém a maioria de seus eleitores e cultiva melhor a socialização através de gerações, família, organizações coletivas (sindicatos, movimentos sociais, ONGs), da "captura" da educação pública e sua influência no ambiente cultural, bem como sua inserção nos circuitos institucionais, em particular no governo de Montevidéu.

\footnotetext{
${ }^{17}$ A natureza híbrida de um "partido de coalizão" pode ser comparada à de outros agrupamentos de esquerda. Mas o esquema coligacional ou federativo ("tribal") pode ser encontrado em partidos de outras tendências, especialmente durante períodos de formação.
} 
Os processos de tomada de decisões seguiram essa parábola de unidade mediante uma árdua disputa. O regime "federal" e baseado em consenso, com representação igual e direitos de veto, deu lugar ao princípio da maioria, com os caudais de votos nas eleições internas e nacionais ganhando cada vez mais peso.

A estrutura de liderança contribuiu para consolidar essa evolução. Embora persista a prática da tomada de decisão coletiva, a liderança personalizada se destaca, exercida pelos candidatos presidenciais comuns, que ganham autonomia e representam o todo. Esses perfis se tornaram mais agudos com a ascensão de Tabaré Vázquez a candidato presidencial, com uma inclinação "populista" e um novo "caudilhismo" de esquerda.

Com essa unidade baseada na coalizão, o FA exibe um alto nível de fracionamento, com vários grupos políticos coexistindo em seu âmago. Isso, em última análise, serve como uma forte rede de arrasto eleitoral, possibilitando que o FA diversifique seus atrativos e mantenha partidários, ao mesmo tempo em que conquista novos eleitores.

\section{Uma estratégia a duas pontas: oposição e competição pelo centro.}

A estratégia de acumulação baseia-se numa certa "dualidade". O êxito do FA deve-se, em larga medida, ao seu desempenho como força hegemônica de oposição e ao seu confronto com os partidos tradicionais, que rejeita compromissos e cresce à medida que aumentam suas chances eleitorais. Mas essa estratégia está articulada com sua transformação política e seu desenvolvimento como partido "catch-all", marcado pela reconversão ideológica e a competição pelo centro.

Passo a passo, a competição inter e intra-partido, o aprendizado político e a experiência de governar Montevidéu levaram à moderação ideológica e a posições pragmáticas, em um movimento que afirma uma nova identidade ideológica e, ao mesmo tempo, conquista eleitores do centro. Com efeito, de 1988 a 1999, o FA dobrou seus votos (chegando a 40\% no primeiro turno de 1999 e a 46\% no segundo turno), mas a proporção de cidadãos que se identificam com a esquerda ou centro-esquerda permanece em torno dos $25 \%{ }^{18}$.

Isso significa que o Frente Amplio estendeu-se para o centro - sem ter ainda sofrido "fugas" para a esquerda ${ }^{19}$ - e a fronteira de seu crescimento está

\footnotetext{
${ }^{18}$ Canzani (2000) mostra que, entre 1988 e 1999, os segmentos da auto-identificação ideológica dos cidadãos mantiveram proporções relativamente estáveis: um terço no centro e sem que a esquerda/centro-esquerda ultrapassasse um quarto do eleitorado.

${ }^{19}$ A única divisão que ocorreu (1989) veio da ala mais moderada, mas não deteve o crescimento do FA. A unidade da esquerda foi recentemente recomposta por meio de um acordo com o Nuevo Espacio. Ao mesmo tempo, manteve-se o apoio entre os trabalhadores e, apesar das contradições, por enquanto não ocorreu o
} 
nesse segmento do eleitorado. Esses parâmetros condicionam as estratégias da esquerda para conquistar o governo, tal como aconteceu em outros países e, de modo mais notável, na disputa que deu a vitória a Lula no Brasil.

É relevante mencionar aqui as observações de Duverger sobre o crescimento da esquerda na França na década de 1930 (deslizamento "real" e "aparente" para a esquerda), que servem como uma espécie de "teorema" político aplicável a evoluções como as que ocorrem no Uruguai e no Brasil: "Sous la Troisième République, les Français ont glissé à gauche, bien sûr; mais la gauche a glissé vers les Français, également: elle a fait la moitié du chemin" (DUVERGER, 1951, p. 340) ${ }^{20}$.

Meu argumento - igual à sentença de Duverger - coaduna-se com os modelos espaciais de Downs sobre as pautas de votação e os formatos de competência partidária, em casos tais como o do Uruguai, que mostram uma curva "normal" de distribuição ideológica, com a maioria dos votantes localizados em posições de centro, na escala esquerda-direita (DOWNS, 1957).

Numa competição de bloco versus bloco, dentro de um formato nãopolarizado, a lógica de "diferença" e oposição coexiste com as tendências no sentido da moderação ideológica e disputa pelo centro.

\section{Paradoxos da prosperidade}

\section{Custos e benefícios do reformismo moderado}

O bloco dos partidos tradicionais desempenhou-se razoavelmente bem na inovação da maneira de governar, na gestão da agenda de reformas e na "reciclagem" de sua elite, incluindo uma reestruturação de suas plataformas programáticas e dos parâmetros de liderança. Além disso, os anos 90 foram um período de estabilidade econômica, declínio de inflação e crescimento cumulativo. A crise atual, que acarreta uma mudança drástica desse cenário, começou a ser sentida depois da eleição de 1999 e explodiu em 2002.

Paradoxalmente, esse sucesso revelou-se custoso e o apoio eleitoral ao bloco declinou sistematicamente. No ano em que o FA apareceu (1971), o PC e o PN juntos conquistaram $80 \%$ dos votos (antes de 1966, costumavam atingir cerca de 90\%). No final da ditadura (1984), totalizaram 76\%. Três eleições depois (1999), o apoio combinado aos dois foi de $55 \%$.

\footnotetext{
"dilema eleitoral" social-democrático (PRZEWORSKI, 1985) - eleitorado trabalhista versus crescimento diversificado.

20 "Na Terceira República, os franceses deslizaram para a esquerda, é certo; mas a esquerda deslizou igualmente no sentido dos franceses: ela fez a metade do caminho" (NT).
} 
Tabela 8

Apoio eleitoral aos blocos (\%) - 1971-1999.

\begin{tabular}{|c|c|c|c|}
\hline \hline & $\begin{array}{c}\text { Partido Colorado } \\
\text { Partido Nacional }\end{array}$ & Frente Amplio & $\begin{array}{c}\text { Frente Amplio } \\
\text { + Nuevo Espacio }\end{array}$ \\
\hline 1971 & 81 & 18 & 18 \\
\hline 1984 & 76 & 21 & 21 \\
\hline 1989 & 69 & 21 & 30 \\
\hline 1994 & 63 & 30 & 35 \\
\hline 1999 & 55 & 40 & 44 \\
\hline
\end{tabular}

Fonte: Instituto de Ciência Política - Banco de Dados.

Dois fatores relacionados pesaram nessa tendência. Em primeiro lugar, a reforma do Estado e a liberalização da economia alteraram a natureza secular dos partidos "de Estado" de corte "keynesiano" e isso causou uma certa redução de seus recursos de poder, em particular no que diz respeito ao alcance, à forma e à discricionariedade política na alocação de bens públicos. Isso modificou o sistema de ligações ("linkages") com os cidadãos, agentes econômicos e grupos sociais. Em segundo lugar, as novas diretrizes para competição e cooperação geradas pelo surgimento do Frente Amplio e reforçadas pelo sistema eleitoral estabelecido em 1996.

Desse modo, pode-se dizer que o declínio eleitoral dos partidos tradicionais ocorre, em parte, como conseqüência de suas próprias estratégias, seja em termos da ofensiva neoliberal que realizam; seja em termos das reações defensivas adotadas diante do crescimento da esquerda (cooperação política e coligações, mudança nas regras eleitorais).

Está claro que esses fatores funcionaram num cenário marcado pelo surgimento do FA: a transformação da esquerda e suas estratégias de competição são elementos centrais para explicar o realinhamento eleitoral ${ }^{21}$. Mas não é menos verdade que, nessa "conjuntura crítica", os partidos tradicionais, mediante ação ou

\footnotetext{
${ }^{21}$ De outro modo, a transição liberal poderia ter levado a evoluções políticas diferentes, como ocorreu em outros países latino-americanos, dependendo exatamente das características e da solidez do sistema partidário, da genealogia dos partidos na direção do processo e dos esforços da esquerda, bem como dos traços dos modelos de desenvolvimento anterior e das condições concretas do ajuste e das reformas.
} 
reação, afetaram os pilares sobre os quais seu domínio se baseou durante todo o século XX.

No que diz respeito à primeira dimensão mencionada, os "males da época" desempenharam um papel que é evidente nos sistemas políticos contemporâneos e que são, com freqüência, percebidos como causa do "declínio" dos partidos. Privatizações, reformas orientadas para o mercado e liberalização econômica, junto com o impacto da integração regional e da globalização, limitam a capacidade e a autonomia do Estado nacional, alterando as relações com a sociedade civil e o mercado interno. A política e os políticos não são mais o que costumavam ser. As atitudes dos cidadãos e dos atores econômicos com respeito à política e aos partidos estão mudando. O individualismo de mercado absorve energias sociais e diminui a ação coletiva. Como ocorreu em outras conjunturas históricas, há "anomia" e "malaise" social, certo desencanto com a política e indiferença em relação aos partidos.

As diretrizes de regulamentação mudam, a ajuda ao capital privado é enfraquecida e o fluxo de bens públicos declina. Muitos serviços que eram anteriormente prestados aos trabalhadores e cidadãos, como benefícios de bemestar e mecanismos de integração social, são transferidos para agentes privados e, mesmo onde permanecem nas mãos do setor público, estão sujeitos a um fluxo de "mercantilização" que despreza a lógica de asignação ou atribuição política.

Em virtude das mudanças em andamento e em conseqüência de seus esforços reformistas, os partidos perdem os recursos que eram propiciados pela intervenção do Estado, durante a era keynesiana. Os poderes que surgem de sua participação direta como agentes públicos e através das conexões entre Estado e atores sociais se enfraquecem: tanto com respeito a prestações seletivas, por meio do clientelismo e das redes corporativas - que não desaparecem, mas mudam de forma e têm o alcance reduzido - quanto, de modo mais amplo, com respeito a programas universalistas e investimentos públicos, políticas reguladoras e distributivas, intermediação de interesses, arbitragem de conflitos, criação de empregos etc ${ }^{22}$.

Os partidos de Estado - mais keynesianos - cuja organização e conjunto de funções dependiam do controle do aparelho estatal, estão limitados em suas capacidades políticas, precisam ajustar-se às mudanças e geram novos padrões para a regulamentação econômica e social. Estes, por sua vez, exigem nova expertise e novos recursos institucionais. Ademais, os partidos encontram dificuldades para reformular sua organização, assumir tarefas de representação, renovar suas funções políticas, padrões de liderança e conexões.

\footnotetext{
${ }^{22}$ Para uma discussão sobre as mudanças atuais em partidos e “linkages”, ver Lawson (1988); Katz (1990) e Kitschelt (2000).
} 
No caso uruguaio, esses processos têm uma incidência importante mas, ao mesmo tempo, são relativamente limitados, devido às características da transição liberal e por motivos que têm a ver com o desempenho de cada bloco partidário, com os padrões de competição e com a vitalidade do sistema partidário como um todo.

Está claro que desde os anos 90, as mudanças no Estado e na economia caminham ao lado da transformação da autoridade política e das funções dos partidos, seus recursos de poder e as margens de discricionariedade que costumavam ter. Isso altera os padrões de ligação ("linkage chains"), as redes clientelistas e as relações corporativistas. Está claro também que a liberalização econômica e a reforma do Estado são um eixo privilegiado no conflito político e na competição partidária. É notável que, numa sociedade profundamente "estatista", as propostas de privatização sejam muito centrais e apareçam como um fator decisivo nos alinhamentos políticos ${ }^{23}$.

Se esse conjunto de transformações contribui para explicar o declínio eleitoral dos partidos tradicionais ${ }^{24}$, por outro lado, há fatores que mitigam ou compensam seus efeitos.

Em primeiro lugar, os partidos tradicionais assumiram a liderança nos processos de mudança e mantiveram eleitores mediante propostas ideológicas renovadas e ligações de tipo programático. Essa reciclagem os levou a agir de modo bastante eficaz como partidos de opinião e agentes de governo, baseados numa alteração da "gramática" da política e legitimação, que potencializa a oposição mas, ao mesmo tempo, alcança aceitação num segmento considerável da cidadania.

\footnotetext{
${ }^{23}$ Cálculos baseados nas estatísticas do Latinobarómetro 1995-2002 (LANZARO e LUNA, 2002) confirmam que, no Uruguai, a clivagem Estado-mercado e a opinião pública sobre privatizações constituem os melhores indicadores de intenção de voto. Com um eleitorado que possui um alto nível de sentimento pró-Estado, os eleitores do FA são mais Estado-cêntricos do que os do PC, PN e NE. De modo análogo, enquanto o FA é associado consistentemente com a defesa do Estado, os partidos tradicionais estão assumindo posições mais centradas no mercado.

24 Valeria a pena fazer uma análise separada para investigar a "racionalidade" que inspira esses comportamentos, o que levaria a um debate mais geral, em referência à América Latina e outras regiões. Há uma vasta literatura normativa em apoio do modelo liberal, mas sabe-se menos sobre as causas concretas que levam os partidos a "amarrar suas mãos" e aplicar as "receitas" ou "pacotes" que acarretam uma redução de seus próprios recursos políticos e implicam amiúde uma reviravolta em relação a suas práticas normais: causas endógenas e exógenas, constrangimentos internacionais e pressões de organizações multilaterais, crises econômicas e fiscais, "revolução cultural", disputa ideológica e "efeito de contágio", a força das "idéias" e a competição política, bem como tipos de partidos e sistemas partidários, traços da forma de Estado anterior e modos de desenvolvimento.
} 
Em segundo lugar, tendo em vista a ausência de uma crise aguda - causa da deflagração de ajustes mais abruptos em outros países - e, em especial, como conseqüência da dinâmica política equilibrada, o impulso liberal foi "amortecido"25. As reformas do Estado foram graduais e moderadas. A privatização e o "recuo" dos serviços públicos e do bem-estar não atingiram a magnitude evidente em outros países. O emprego público formal foi reduzido, mas não drasticamente cortado, e apareceram modalidades "laterais" de contratos estatais e para-estatais, muitas vezes com novas formas de clientelismo. A década de crescimento econômico foi acompanhada por políticas sociais que reduziram a pobreza e mitigaram as desigualdades, conseguindo uma certa melhora na distribuição de renda ${ }^{26}$.

As privatizações, terceirizações e organizações não-governamentais reformularam o sistema de mediações ("linkages") que existia há muito tempo entre o Estado, o mercado e a sociedade civil. Mas algumas empresas e os serviços sociais continuam nas mãos do Estado, embora não gozem mais da situação de monopólio. Dentro do setor público, há uma impulso "de mercado" e uma penetração da lógica privada e de uma "nova gestão pública" (privatização "suave", "mercantilização"). A influência dos gerentes e da tecnocracia está crescendo, estabelecendo novos termos para a velha dicotomia entre política e administração. Contudo, os partidos permanecem na direção da gestão pública, mantendo seus cargos nos conselhos das empresas estatais e outros órgãos do governo. Assim, mesmo com limites mais apertados, há ainda margem para condução política e para antigas e novas formas de clientelismo.

\section{Implicações para a clivagem esquerda-direita}

As ações do Frente Amplio causaram um grande impacto sobre esses aspectos e em relação à consistência do sistema político. Seu poder de oposição além dos movimentos de resistência que surgiram no interior dos partidos do establishment - contribuiu para evitar que as reformas tivessem uma inclinação liberal mais pronunciada, limitando as iniciativas de privatização ou bloqueando-as por meio de referendos populares.

\footnotetext{
${ }^{25}$ A crise que iniciou em 2000 e atingiu seu clímax em 2002 pode ter dado origem a um impulso mais radical. Porém, embora a crise tenha levado a ajustes muito rígidos, um tom moderado continua a predominar com respeito às medidas econômicas, políticas sociais e privatizações: em função dos equilíbrios políticos o gradualismo uruguaio eppure si muove ... !

${ }^{26}$ Nos anos 90, o Uruguai foi o único país latino-americano que viu a distribuição de renda melhorar com o aumento do PIB. De acordo com relatórios disponíveis (CEPAL, PNUD), os indicadores sociais do país mostram uma evolução favorável, conquistando posições elevadas no Índice de Desenvolvimento Humano e no Índice de Pobreza.
} 
Seu desenvolvimento como partido emergente, com crescentes frutos eleitorais, abrange as forças de oposição e tende a monopolizá-las, evitando a fragmentação e propiciando uma estrutura receptiva para os grupos que desertam dos partidos tradicionais.

Esse desenvolvimento provoca expectativas de alternância e mudança no curso do governo, que canaliza o "descontentamento" e serve para conter, enquadrar ou retardar as ações dos sindicatos e movimentos sociais, bem como o surgimento de novas formas de organização e de protesto "espontâneo" ou "selvagem". Embora o peso dos sindicatos tenha diminuído e o controle partidário seja mais frouxo, a "fraternidade" dos setores de esquerda com os trabalhadores e outros grupos entra em jogo. A influência do FA tende mesmo a se ramificar, abrangendo velhas e novas questões (cooperativas, feminismo, direitos humanos etc.). Suas ações no governo de Montevidéu também são importantes. A expansão dos serviços públicos e das políticas sociais, confiadas a órgãos municipais, centros comunais descentralizados e ONGs politicamente afins produziram resultados eleitorais que renovaram as redes de clientela e "parentela".

Esses laços diretos combinaram-se com repercussões "indiretas" que surgem não como resultado de afinidades, mas de dissenso. As posições cada vez mais moderadas da esquerda reduziram o "potencial de ameaça" que o FA poderia significar para os empresários e as associações empresariais. As últimas amenizaram a resistência, iniciando relações com líderes da esquerda (foram realizadas algumas aproximações notáveis) e, diante de uma eventual vitória eleitoral do FA, tendem, no máximo, a fechar fileiras com os partidos tradicionais. Também de modo indireto, a pressão da oposição contribui para a manutenção da integridade do sistema partidário e de sua capacidade de agregação.

A nova composição do sistema partidário mantém a polaridade e "atração" da competição política. Mesmo sem polarização, dentro de um quadro de distâncias ideológicas moderadas e de batalha pelo centro, a clivagem esquerdadireita serve de eixo para a competição interpartidária e para o alinhamento eleitoral ${ }^{27}$. O reconhecimento explícito e a diferenciação da elite partidária e dos eleitores seguem esse espectro, baseado em discursos e programas, bem como em atitudes relacionadas com valores e questões estratégicas da agenda política, especialmente a reforma do Estado e as privatizações ${ }^{28}$.

\footnotetext{
${ }^{27}$ No segundo turno das eleições presidenciais de 1999, o candidato vencedor - Jorge Batlle - obteve a maioria dos votos da direita $(93 \%)$ e da centro-direita $(89 \%)$. O candidato do Frente Amplio - Tabaré Vázquez monopolizou a esquerda (97\%) e a centro-esquerda (93\%). O voto dos centristas inclinou-se mais para Batlle (52\%) do que para Vázquez (36\%). Ver Canzani (2000).

${ }^{28}$ O Uruguai - juntamente com o Chile - é um dos países latino-americanos onde a clivagem ideológica esquerda-direita mostra significação consistente e é aceita como tal nas pesquisas de opinião pública e surveys de cultura política, com relação à identidade e a auto-identificação da elite e dos cidadãos (LANZARO e LUNA, 2002).
} 
Essa tendência contribui para recriar o padrão de competição da era do bipartidarismo tradicional entre as posições mais conservadoras do PN e o liberalismo social do PC, dentro do qual o "progressismo" das frações "batllistas"29 pesa muito. Essa mudança sugere um novo padrão de bipolaridade, que o regime eleitoral estabelecido pela reforma constitucional de 1996 ajudou a consolidar.

$\mathrm{Na}$ medida em que o FA cresce, blancos e colorados - que foram rivais ao longo da história uruguaia - passam por um processo de "convergência". Arquitetam compromissos e coalizões, compondo um pólo político e uma família ideológica com proximidade mútua e uma relativa falta de diferenciação ${ }^{30}$. Em conseqüência da sobreposição ideológica e da associação política, encontram dificuldades para cultivar suas identidades e tradições ou para articular opções diferentes e competir entre eles mesmos. Também diminui a diferenciação interna assim como as possibilidades de arregimentação de votos propiciadas pela coexistência de alas de direita e de esquerda dentro dos partidos tradicionais. A diversidade persiste no interior de ambos e a dissidência interna impõe compromissos e obstrui certas iniciativas políticas. Mas, dado o estreitamento do apoio eleitoral e da representação parlamentar, a competição com o FA e os deveres de governo promovem uma convergência maior entre frações e a necessidade de uma maior disciplina partidária. A bipolaridade gerou fenômenos de concentração interna e prejudicou as alas mais progressistas dos dois partidos tradicionais.

O regime eleitoral estabelecido pela reforma de 1996 alimenta essas complicações e impõe novas exigências. Embora a eleição presidencial por maioria de votos pudesse ter um efeito de rede, a competição no primeiro turno das eleições e a representação parlamentar proporcional estão abertas à pluralidade partidária. Mas isso exige que os partidos vizinhos tenham um certo peso político e sua própria linha para competir com eficácia. O novo limite de apresentação de um candidato presidencial por partido reduz a possibilidade da diferenciação política entre as frações partidárias, obrigadas a se alinhar com o vencedor das eleições primárias, o que afeta o perfil individual de cada setor interno, reduzindo a capacidade de arregimentação de votos.

\footnotetext{
${ }^{29}$ Referência às frações históricas mais progresistas do Partido Colorado. Uma linha que teve seu momento originário no início do século XX - com a figura do seu fundador José Batlle y Ordóñez (Presidente 1903-07 e 1911-15: "primeiro batllismo") - e foi seguida por Luis Batlle Berres (Presidente 1947-50 e 1954-58: "segundo batllismo"). O filho deste último, o atual presidente Jorge Battle (2000-2005), tem ignorado a tradição estatista do "batllismo" e é um dos paladinos do neoliberalismo vernáculo.

${ }^{30}$ A superposição entre o PC e o PN, que em 1984 era de $77 \%$ do eleitorado, atingiu $90 \%$ em 1999 . No mesmo período, a distância ideológica entre os dois caiu de $12 \%$ para $3,3 \%$. De acordo com os critérios de Sartori, desenha-se um círculo de família, uma vez que a superposição ultrapassa a marca dos $85 \%$ e a distância é menor do que $5 \%$ (cálculos baseados em pesquisas de Equipos-Mori e Cifra).
} 
Nesse cenário, os dois partidos do establishment e mesmo sua combinação perderam votos. Porém, o pólo político que eles formam encontra um fulcro na estrutura de competição direita-esquerda. O desenvolvimento do FA como partido desafiante fornece os elementos de vitalidade ao sistema partidário e, mesmo subtraindo votos do bloco tradicional, pode também, paradoxalmente, servir de incentivo para sua reprodução.

A evolução de cada partido, as relações entre eles e o perfil do bloco que compõem - a possibilidade de reter votos e até de reverter o declínio eleitoral, que não é um destino inevitável - dependem da produtividade que desenvolverem nesse quadro competitivo, da sua reorganização, de suas plataformas políticas e de suas alternativas de liderança.

\section{Frente Amplio: as contradições do sucesso}

O FA é um partido bem sucedido, mas se defronta com desafios que surgem do próprio crescimento e dos parâmetros de competição. Estes são semelhantes aos enfrentados pelos partidos de oposição - em especial se são "novatos" e, em particular, os partidos de esquerda com aspirações a conquistar o governo quando agem no quadro da democracia competitiva, dentro de um sistema institucionalizado e consistente, sem extremos de polarização.

A acumulação do FA baseou-se na lógica da oposição, combinada com moderação ideológica e suas outras evoluções como partido "catch-all". O FA alcançou "função governamental" por meio de certas ações políticas, do trabalho parlamentar e da administração municipal. Mas, na competição com os partidos tradicionais e as coligações governantes, à medida em que suas chances eleitorais aumentam, ele tem tido mais incentivos para se opor do que para cooperar. A "perseguição por políticas" perdeu terreno para a "perseguição por votos", que favorece o confronto, sem postura radical, mas com um "antagonismo" que se intensifica em relação às reformas estruturais. Fortalece-se uma cultura de oposição baseada, em larga medida, em "princípios" e posições defensivas.

Essas premissas de acumulação deram resultados e certamente continuarão a dar. Porém, os constrangimentos da competição e a dinâmica do próprio desenvolvimento político exigem que o FA também refine a combinação de oposição e moderação ideológica, melhorando sua projeção como ator de governo, ampliando a confiança política e as iniciativas "positivas". Com relação a isso, a crise que começou em 2000 pode melhorar suas chances, mas também apresenta demandas maiores num horizonte repleto de dificuldades. 
Nesse sentido, um fator-chave está nas regras institucionais. A eleição presidencial majoritária impõe ex profeso uma barreira mais alta para conquistar a presidência. Ademais, embora reforce a bipolaridade política, esse regime não conduz necessariamente à polarização ideológica. Ao contrário, resulta geralmente numa competição centrípeta, quando não numa convergência programática, voltada para as preferências moderadas de um cidadão "médio" e, em particular, dos eleitores centristas, que se tornam decisivos.

Por fim, não devemos esquecer as mudanças provocadas pela atual transição histórica da economia, do Estado e da política. Em oposição aos partidos que lideram essa "modernização", o FA tem cultivado a "lógica da diferença", com um pé nos valores tradicionais, e tem se beneficiado com isso. Mas esses movimentos promovem um certo nível de assimilação cultural que pesa sobre as fileiras do FA e sobre os segmentos de eleitores "modernos", seu alvo na batalha pelo centro. Há novos valores e disciplinas, constrangimentos internos e internacionais, exigências de responsabilidade política que estabelecem condições não só para o governo, mas também para aqueles que buscam conquistá-lo.

Se vier a ocorrer alternância no poder, o FA terá de encarar essas condições e os partidos tradicionais tornar-se-ão oposição, num cenário que levará à reformulação das coordenadas do sistema político, resultando em outros desafios e novas questões.

Nesse caso, pode-se apostar que o FA terá de fazer ajustes sensíveis em sua direção ideológica e nas suas orientações políticas. Ademais, dada a composição do sistema de partidos e as regras constitucionais, é muito difícil que o FA possa governar sem compromissos e acordos parlamentares com setores dos outros partidos. A experiência poria à prova a capacidade de agregação do $F A$, seu formato de organização e a "colagem" de frações políticas que o compõem, assim como os vínculos com o movimento sindical.

O diagrama de relações e o sistema político que o próprio FA conforma têm resultados efetivos para atuar na oposição e na fase de acumulação eleitoral. Eventualmente, será necessário observar em que medida esse sistema mantém sua vigência e que transformações experimenta, no caso de o FA ter de enfrentar as tarefas de governo. Nessa perspectiva, a trajetória dos partidos de esquerda que chegaram ao poder no Chile e no Brasil proporciona um ponto de referência significativo. 


\section{Bibliografia}

ABRANCHES, Sérgio H. Presidencialismo de coalizão: o dilema institucional brasileiro. Dados, Rio de Janeiro, n $1,1988$.

ALCÁNTARA, Manuel \& FREIDENBERG, Flavia. Los partidos políticos en América Latina. Salamanca: Universidad de Salamanca, 2001.

CANZANI, Agustín. Mensajes en una botella: analizando las elecciones de 1999-2000.In Elecciones 1999-2000. Montevidéo: Instituto de Ciencia Política, Ediciones de la Banda Oriental.

CASTLES, Francis e WILDENMANN, Rudolf (eds.). The Future of Party Government. Berlim: de Gruyter, 1986.

CHASQUETTI, Daniel. La renovación del Parlamento, 1985-1999. Montevidéo: Instituto de Ciencia Política, Working Paper, 2000.

COLLIER, David e COLLIER, Ruth Berins. Shaping the Political Arena. Princeton: Princeton University Press, 1991.

COPPEDGE, Michael. Latin American Parties: Political Darwinism in the Lost Decade. In DIAMOND, Larry \& GUNTHER, Richard (eds.). Political Parties and Democracy. The Johns Hopkins University Press, 2002.

DAHL, Robert. A Preface to Democratic Theory. Chicago: University of Chicago Press, 1956.

Polyarchy: Participation and Opposition. New Haven: Yale University Press, 1971.

DOWNS, Anthony. An Economic Theory of Democracy. New York: Harper Collins, 1957.

DUVERGER, Maurice. Les partis politiques. Paris: Armand Colin, 1951.

GONZÁLEZ, Luis E. Los partidos establecidos y sus desafiantes. In Los partidos políticos uruguayos en tiempos de cambios. Montevidéo: Universidad Católica, 1999.

GRAMSCI, Antonio. Note sul Machiavelli, sulla politica e sullo stato moderno - Quaderni del Carcere. Roma: Editori Riuniti, 1971. 
GUNTHER, Richard \& DIAMOND, Larry. Species of Political Parties: A New Typology. Party Politics - 9/2, 2003.

KATZ, Richard. Party as linkage: A vestigial function?. European Journal of Political Research, 18, 1990.

KATZ, Richard e MAIR, Peter. Changing Models of Party Organization and Party Democracy. The Emergence of the Cartel-Party. Party Politics, 1-1/1995.

KITSCHELT, Herbert. Linkages between Citizens and Politicians in Democratic Polities. Comparative Political Studies, $33 \cdot 6 / 7,2000$.

KIRCHHEIMER, Otto. The Transformation of Western European Party System. In LAPAlOMBARA, Joseph e WEINER, Myron (eds.). Political Parties and Political Development. Princeton: Princeton University Press, 1966.

LANZARO, Jorge. Parties, State and Politics in Uruguay (1985-1993). Barcelona: Institut de Ciències Politiques i Socials, Working Papers 90, 1994.

. La izquierda uruguaya: de la adscripción corporativa al desarrollo de un partido de nuevo tipo. Montevidéo: Instituto de Ciencia Política, Working Paper, 1996.

La "segunda" transición en el Uruguay. Gobierno y partidos en un tiempo de reformas. Montevidéo: Fundación de Cultura Universitaria, 2000a.

.El Frente Amplio: entre la lógica de oposición y la lógica de gobierno. Revista Uruguaya de Ciencia Política 12, 2000 b.

Tipos de presidencialismo y coaliciones políticas en América Latina. Buenos Aires: Clacso, 2001.

LANZARO, Jorge e LUNA, Juan Pablo. Uruguay: las claves de crecimiento del Frente Amplio. Trabalho apresentado no seminário "Democracia y Opinión Pública en América Latina". Buenos Aires, Latinobarómetro-Clacso, 2002.

LAWSON, Kay. When Linkage Fails. In LAWSON, Kay e MERKL, Peter (eds.). When Parties Fail: Emerging Alternative Organizations. Princeton: Princeton University Press, 1988.

LIJPHART, Arendt. Consociational Democracy. World Politics, XXI/2, 1969. 
Democracies. New Haven: Yale University Press, 1984.

MAINWARING, Scott. Presidentialism and Multipartism: The Difficult Combination. Comparative Political Studies, 26, 1993.

MAINWARING, Scott e SCULLY, Timothy. Building Democratic Institutions: Party Systems in Latin America. Stanford: Stanford University Press, 1995.

MAIR, Peter. Party System Change. Nova York: Oxford University Press, 1997.

NEUMANN, Sigmund. Sistemas de partidos y grados de integración. In LENK, Kurt NEMANN, Franz (eds.). Teoría y sociología críticas de los partidos políticos. Barcelona: Anagrama, 1980.

PANEBIANCO, Angelo. Modelli di partito. Organizzazione e potere nei partiti politici. Bolonha: II Mulino, 1982.

PIZZORNO, Alessandro. I soggetti del pluralismo. Bolonha: II Mulino, 1980.

PRZEWORSKI, Adam. Capitalism and Social Democracy. Cambridge: Cambridge University Press, 1985.

SARTORI, Giovanni. Ingeniería Constitucional Comparada. México: Alianza, 1994.

SOTELO, Mariana. La longevidad de los partidos tradicionales uruguayos. In Los partidos políticos uruguayos en tiempos de cambios. Montevidéo: Universidad Católica, 1999. 